\title{
RASGOS ESPECÍFICOS DE LAS DRAMATURGIAS FEMENINAS EN EL MAGREB: FATIMA GALLAIRE, JALILA BACCAR Y AICHA HAROUN YACOUBI
}

\author{
SPECIFIC FEATURES OF MAGHREBIAN'S DRAMATURGIES: \\ FATIMA GALLAIRE, JALILA BACCAR AND AICHA \\ HAROUN YACOUBI
}

\section{Aicha HAROUN YACOUBI}

\author{
Universidad de Granada \\ aichayaco@hotmail.com
}

Resumen: El objetivo de este artículo es contribuir a una aproximación crítica a la obra dramática de Fatima Gallaire, Jalila Baccar y Aicha Haroun Yacoubi, partiendo de la idea de que en el discurso de las dramaturgas magrebíes, al igual que en otros países, se concibe una ruptura con la tradición literaria y teatral dominante ${ }^{1}$.

\footnotetext{
${ }^{1}$ El presente artículo forma parte de la tesis de doctorado, Dramaturgia femenina en el Magreb: Fatima Gallaire, Jalila Baccar y Aicha Haroun Yacoubi (2012), dirigida por el profesor Francisco Linares Alés, en el Departamento de Lingüística General y Teoría de la Literatura, de la Universidad de Granada.
} 


\begin{abstract}
The aim of this article is to contribute to a critical approach to the dramatic work of Fatima Gallaire, Jalila Baccar and Aicha Haroun Yacoubi, starting from the idea that the discourse of the Maghrebian women playwrights, as in other countries, conceives a break with the literary and theatrical dominant tradition.
\end{abstract}

Palabras clave: Dramaturgas. Magreb. Postcolonial.

Key Words: Women playwrights. Maghreb. Postcolonial.

\title{
1. DOMINACIÓN Y EXCLUSIÓN: REPERCUSIÓN EN LA ESCRITURA DE MUJERES
}

La escritura dramática y escénica contemporánea en el Magreb se halla en movimiento permanente, buscando proporcionar medios, conquistar un público de masas y superar las dificultades internas planteando la diversidad como punto de encuentro. En este marco y contrariamente a las antologías de autores teatrales y estudios publicados, que constituyen un claro ejemplo de exclusión de las dramaturgas, contemplamos una producción dramática y teatral femenina relevante.

La exclusión de la que es objeto la dramaturga magrebí, es una situación que no dista de aquella otra vivida por las autoras en otros países. En España, por ejemplo, según Ángel Berenguer (1999: 10), la dramaturgia femenina era un ejemplo claro de la práctica eliminación de las creaciones teatrales no hegemónicas en la historización del teatro español. No obstante, a finales del siglo pasado, este país conoce un gran avance en la escena teatral y con ello, como diría Valeria Lo Porto (2012: 372), llega también «la posibilidad de conceder voz pública a las dramaturgas y, consecuentemente, la exhibición de sus obras que hasta este momento, habían quedado silenciadas por los agentes sociales». Esto ha dado lugar a que en estas dos décadas finales del siglo XX e inicios del XXI, se inicie una intensa labor de investigación en torno a esta escritura de autoría femenina.

A este respecto, cabe mencionar el proyecto europeo Dramaturgae del que es promotor el profesor José Romera Castillo y en el que participan tres Instituciones: la UNED, la Universidad de Toulouse y la Justus-Liebig Universität Giessen. Fruto de las investigaciones llevadas a cabo en este marco, del 2005 al 2008, aparecen tres publicaciones que mencionamos a continuación: José Romera Castillo (ed.), Dramaturgias femeninas en la segunda mitad del siglo XX: espacio y tiempo (Madrid: Visor Libros, 
2005) ${ }^{2}$; Roswita / Emmanuel Garnier (ed.), Transgression et folie dans les dramaturgies féminines hispaniques contemporaines (Carnières-Morlanwelz: Lansman Éditeur, 2007) y Wilfried Floeck et alii (eds.), Dramaturgias femeninas en el teatro español contemporáneo: entre pasado y presente (Hildesheim, Alemania: Olms, 2008).

Tratar una dramaturgia magrebí específica de mujeres implica recorrer el contexto donde ésta aparece y evoluciona, aspecto que va relacionado con la reciente inserción en el sistema literario de las escritoras en general. Éstas, se inscriben dentro de un marco determinado que aún vincula su producción a su condición sexual. Una situación generalizada para toda expresión femenina, pero que ha tenido más mella en la escritura: por la temática empleada, por la estética, por la construcción de imágenes, por su discurso y por el lenguaje que emplean. Por ser este mismo lenguaje lo que se considera subversivo para la cultura dominante.

El aspecto subversivo se desprende de una creación concebida como ruptura con lo tradicionalmente impuesto, al presentar una problemática relacionada con el peso de la tradición y cuestionan las normas impuestas por aquellos que persiguen los fines canónicos y rígidos de la cultura dominante. Las mujeres, en cuanto autoras, no niegan la tradición, la discuten y se enfrentan al discurso androcéntrico para liberarse, mediante el discurso literario y teatral, del yugo al que se las ha sometido durante siglos. Es un discurso que Jacinta Escudos en «¿Subversión, moda o discriminación?: sobre el concepto de literatura de género» (2003), define como espacio arrebatado al silencio que busca desahogar lo que el lenguaje verbal, la supuesta moral y las buenas costumbres, impiden expresar. Para esta autora, «la persona que escribe es doblemente subversiva porque piensa y dice, cuando se supone que no debe hacer ninguna de las dos cosas». Esto corrobora de alguna manera la opinión de Mdarhi Alaoui, el cual, en «Approche du roman féminin au Maroc: historique, dénomination et réception de la littérature féminine» (2001), afirma que el malestar ante la producción de género en el mundo árabe viene dado por el hecho de que las mujeres ya no sólo dominan un bagaje oral, sino que, en los últimos tiempos, también lo escritural que siempre ha estado ligado a lo sagrado, por lo tanto al poder.

Según este estudioso, cuando el crítico convencional se pronuncia ante la escritura femenina, aplica términos como de rango inferior, ornamental y superficial. Este prejuicio social, más que una crítica objetiva, conlleva el

\footnotetext{
${ }^{2}$ Cf. además Romera Castillo, ed. (2012).
} 
considerar la expresión artística de las mujeres como una producción que no alcanza a profundizar en temas que afectan a su país o al mundo. No obstante, alega Alaoui, las escritoras rompen la estructura de la tradición masculina $y$, al igual que sus compañeras en países donde existe mayor tradición literaria y dramática, escriben a partir de lo que les impacta, abarcando temas comunes, pero tratados con un estilo y un lenguaje que le son propios:

Dans la période actuelle, tout lecteur constatera que les oeuvres féminines ne sont pas une simple reproduction de la littérature masculine. Bien qu'elles aient des thèmes communs avec la littérature masculine (retour sur l'histoire coloniale, critiques des abus de pouvoir, contestation de certaines traditions négatives pour l'ensemble de la société aspiration à une vie moderne), ces thèmes sont relativement traités différemment (Mdarhi, 2001).

Esta literatura femenina no necesariamente tiene que imitar los esquemas del pensamiento masculino musulmán como discurso que mantiene la corriente de arabistas más conservadora, simplemente porque la mujer posee sus propias normas y una lógica que difiere de la visión del hombre. La escritura femenina, sin ser diferente, se inscribe dentro de lo que se puede denominar una variedad o alternativa a otra visión ya existente. De modo que la posición que mantiene la tradición crítica magrebí, a nuestro entender, se considera lejana de la realidad social, étnica y lingüística de las escritoras norteafricanas. Consideramos que el juicio todavía común, en relación con una dramaturgia femenina, es arbitrario ya que carece de fundamentos científicos porque no se atiene a los textos y a la producción en curso $^{3}$. De hecho, no se ha realizado un estudio de tales obras -excepto los estudios llevados a cabo por universitarias extranjeras sobre la producción de dramaturgas surgidas de la inmigración ${ }^{4}-$, lo que a nuestro parecer permite suponer equivocada la posición del estudioso magrebí ante una producción que, si bien es reciente, presenta una solidez que la hace digna de la investigación.

${ }^{3}$ Interesa más para efectos institucionales la formación de un teatro nacional con su historia y su canon que en muchos casos resulta de traducciones de textos occidentales que atender a la realidad que siempre es problemática.

${ }^{4}$ A título de ejemplo citamos el estudio realizado por Anne Schmidt (1998a), Le miroir de l'autre: une nouvelle génération de femmes dramaturges issue de la migration à Paris au XXème siècle. 


\section{APROXIMACIÓN A TRES AUTORAS}

La dramaturga magrebí plantea con su creación una aspiración que ella considera legítima e irrenunciable: el mundo visto desde su óptica. Aunque parezca un tópico afirmar que la actividad artística responde a una necesidad de expresión, aquí no se trata ya de que determinadas mujeres se adhieran, aportando su impronta, a un lenguaje ya establecido. Se trata sobre todo de la apertura de un nuevo espacio. El teatro configura ese nuevo espacio de expresión libre, y su originalidad reposa en una cuestión que hasta la actualidad no se había tomado en consideración y es su posición como ciudadana. Ésta, al manifestarse, lo hace bajo su visión como mujer y ente político formando parte de una sociedad y no fuera de ella. Al hacerlo, rompe barreras ${ }^{5}$, sobre todo según aquellos que defienden una legitimidad basada en la Norma, los cuales ven en su discurso una amenaza en contra de la tradición.

En el proceso de escritura la mujer intenta su autonomía buscando modelos alternativos que la identifican y con los que ella se identifica. En dicha búsqueda de cultura y lenguaje alternativos, a través de los cuales intenta expresar su identidad, no necesariamente niega el discurso que la somete, sino que recurre en ocasiones al componente irreductible -esto es, difícilmente descodificable por el hombre- que se da en ciertas asunciones del discurso dominante por parte de la mujer relegada. Si por las razones que sean -negación o utilización desafiante- las elecciones de las escritoras son contrarias a las de la cultura masculina, es porque realmente existe una cultura femenina que intenta dialogar, negociar con el hombre. Esto mismo es aplicable a los textos dramáticos y a la escritura escénica. Esta búsqueda alternativa se da también en la traslación de la obra al escenario.

En razón de lo dicho, los textos dramáticos femeninos se convierten en un lugar heterogéneo respecto a la tradición. Ciertos elementos de heterogeneidad es lo que intentaremos desvelar desde el análisis de los elementos y componentes básicos como son la temática, los personajes y el rasgo linguístico en los textos de tres dramaturgas: Fatima Gallaire (F.G.), autora argelina con una prolífica trayectoria dramática y como ejemplo de una de las autoras del exilio literario; la tunecina Jalila Baccar (J.B.) y la marroquí Aicha Haroun Yacoubi (A.H.Y.), en cuanto dramaturgas que, además de escribir en sus respectivos países de origen, conciben una escritura surgida para el escenario y a partir de la experimentación -tendencia que ha tenido como

${ }^{5}$ Al decir «barreras» nos referimos al hecho de que rompe entre el espacio privado y público y la barrera de los propios cánones literarios, las normas sociales, etc. 
precursora a la tunecina Raja Ben Amar durante los años 80-, lo que nos permite dar una visión más amplia y diversa de esta dramaturgia en efervescencia.

\subsection{Fatima Gallaire-Bourega}

Pese a la iniciativa llevada a cabo por dos precursoras como Myriem Ben o Najía Thameur en los años sesenta, éstas pasaron desapercibidas tanto en el Magreb como en el extranjero. De modo que F.G., es la primera dramaturga que contribuye en gran medida al conocimiento de una literatura dramática escrita por mujeres de origen magrebí. Ésta nació en El Harrouch (Constantina) en 1944. Después de realizar estudios en la Universidad de Argel, viaja a Francia para estudiar cine en la Universidad de París VIII de Vincennes. En 1970 vuelve a Argelia y obtiene el puesto de agregada cultural en la cinemateca de Argel. En 1978, decide volver a Francia y se instala definitivamente en París donde reside en la actualidad.

F.G. se da a conocer en el ámbito literario, a partir de los años 80, llegando a convertirse en una de las autoras magrebíes de mayor prestigio y reconocimiento internacional. Es la primera mujer árabe que logra ser miembro de la Academia Internacional de Autores Dramáticos Châtillon-sur-Chalarone y miembro de Escritores Asociados al Teatro en Francia. A lo largo de su carrera y con un amplio repertorio de teatro, relato y cuento, esta autora argelina recibe numerosos premios de los cuales citaremos los siguientes: el Premio SACD Nuevo Talento en 1987, el Premio Arletty en 1990 por el conjunto de su obra, el Premio del Sindicato de la crítica por la mejor obra francófona, al montaje de Jean Pierre Vincent en 1991 de Princesses, el Premio Malek Haddad de la Fundación Nordin Aba en 1993 y el Premio AMIC de la Academia Francesa por el conjunto de su obra en 1994.

Perteneciente a una generación de transición entre el período colonial y la Independencia, esta autora se enfrenta al doble discurso social: el heredado de Francia durante la época colonial y el arabizante. La escritura supone, según sus propias palabras (véase Serhane y Gallaire, 1993: 13-14), una reacción, por una parte, ante la tragedia personal de ver a su padre torturado y personas cercanas asesinadas durante la Guerra y, por otra, el desasosiego de no ajustarse a las normas establecidas y al discurso político islamizante que se instala en el país. En 1986, y después de haber publicado varios relatos cortos, la autora escribe su primer texto dramático Ah! Vous êtes venus... là où il y a quelques tombes o Princesses, título por el que se da a conocer la pieza a partir de 
1991. La obra, que trata el debate generacional producido por la fuerte influencia de la tradición sobre hombres y mujeres, fue concebida a modo de denuncia de ciertos abusos engendrados por la creencia islámica más conservadora. Una temática que aborda la autora en varios de sus textos con la intención de reflejar una realidad no superada en Argelia: la presencia del extranjero es motivo de hostilidad, y el argelino se intenta proteger de ella erigiéndose en guardián de la tradición islámica como medida.

La mujer y Argelia constituyen la médula temática de gran parte de sus obras tales como La Fête virile (Fiesta viril, 1990), Rimm la gazelle (Rimm, la gacela, 1991), Au coeur, la brûlure (En el corazón, la llaga, 1991), Les coépouses (Coesposas, 1998), La beauté de l'icône (La belleza del icono, 2003), o Les portes de Constantine (Las puertas de Constantina, 2005). Aunque cabe decir que no siempre alude a Argelia como referente real, en algunos títulos como Molly des sables (1994), obra dirigida por Isabelle Starkier y representada en Théâtre Essaïon (París), la protagonista, personaje inspirado en Molly Bloom de James Joyce, es una mujer de origen judío casada con un marroquí. Molly es un personaje complejo que se halla, según esta directora de escena (1994), «écartelée entre sa culture juive et sa culture musulmane, entre ses racines, en Afrique du nord et sa vie, maintenant à Paris. Elle nous parle de son pays, de sa maison et les êtres qui lui sont chers. Et durant son récit, elle incarnera différentes personnes, accumulant dans cette boulimie de souvenirs les vêtements qui les symbolisent».

En Richesses de l'hiver (Las riquezas del invierno, 1990), la acción transcurre en una aldea italiana. El texto, que, bajo nuestro punto de vista, presenta analogías con la trama y los personajes de La casa de Bernarda Alba de F. García Lorca, describe la soledad de cuatro hermanas que viven encerradas en su casa bajo la autoridad del padre/Alba. La menor de éstas decide escapar y cambiar su vida al lado de un extranjero (un príncipe marroquí). Las otras tres hermanas ven los años transcurrir mientras cuentan una a una las botellas de aceite, el fruto de una tierra fértil pero condenada a la sequía, metáfora de la opresión en la que viven las protagonistas de la obra.

Y en Amour et Talisman (El talismán del amor, 1993), la historia se ambienta en Marruecos y narra, con la sencillez y los ingredientes de un cuento, la historia de Izza. Ésta, presa de su egoísmo y de los celos maternos, cae en la tentación de hacer uso de un talismán para romper el compromiso de su único hijo, Yacine, con su enamorada Amina.

En estas tres obras la autora cambia de escenario, pasea sus personajes por distintos países y culturas, enfrenta a mujeres de varias generaciones, combina los elementos tradicionales y modernos, el color de piel y las cre- 
encias, etc. Responde a un intento de ésta por proyectar una temática relacionada con la mujer mediterránea en general y recalcar un universo de mujeres que, aunque pertenecientes a culturas diversas, viven dentro de un espacio limitado a la ausencia. En este recorrido describe una problemática universal a través de una relación de dualidades y dicotomías entre Occidente-Oriente, una característica que la aproxima a su doble identidad frente a la negación de la otra cultura por el discurso dominante en Argelia. La dicotomía se da a nivel de los conceptos hombre/mujer, siendo presentado lo masculino como causante del mal. No es la única manera en que Gallaire relaciona las oposiciones, pues según alega I. Starkier (1994), ésta «concilie, par une écriture majeure, tous les inconciliables: le Nord et le Sud, le Noir et le Blanc, le Faible et le Fort, l'Homme et la Femme, le Dit et l'Indicible...».

\subsection{Jalila Baccar}

Nacida en Túnez capital en 1952, J.B. pertenece a la generación de artistas que descubren el teatro en las aulas del colegio durante los años 60 , período que coincide con la nueva reforma social y cultural promovida por el Presidente de la República, Habib Bourguiba, que incluye el desarrollo de las artes escénicas en Túnez. La autora, después de cursar estudios de Letras en la Escuela Normal Superior, decide dedicarse a la carrera de actriz. En 1973 se incorpora al «Théâtre Sud de Gafsa» (Teatro Sur de la ciudad de Gafsa), compañía de carácter independiente, subvencionada parcialmente por el Estado, donde coincide con el que será su esposo y compañero artístico hasta el momento actual, Fadhel Jaïbi.

Con su adhesión a esta compañía, J.B. entra a formar parte de un círculo de intelectuales que pretenden, entre otras cosas, descentralizar el teatro en este país, haciendo llegar este arte a gran parte de la población tunecina y con recursos que le son propios. Dramaturgos como Fadhel Jaziri, Mohamed Driss, Habib Masriki, Fadhel Jaïbi, Tawfik Jaïbi, Raja Ben Amar ${ }^{6}$, junto a ar-

\footnotetext{
${ }^{6}$ Raja Ben Amar proviene del vivero que constituía el teatro escolar de los años 60 a los 80 . Vive la aventura teatral «Théâtre de Kef» en tiempos de su fundador Monsef Suissi. Posteriormente, y, después de la desintegración de este grupo regional, participó como actriz junto a Jalila Baccar en el recién fundado «Nouveau Théâtre de Tunis» con la obra L'Instruction. En 1980 creó con Monsef Sayem «Théâtre Phou», la segunda compañía profesional privada de Túnez (después del Nuevo Teatro), destacando como animadora del teatro privado (Independiente) tunecino. Al crearse el espacio Madart en Cartago, realiza un encuentro entre teatro y danza, elemento que influye considerablemente en sus creaciones hasta el punto, como diría Abi Sahb, «de anular no sólo el texto sino el teatro mismo» (véase Abi Sahb, 1996: 26). Junto a su compañero Monsef Sayem, Ben Amar es una de las creadoras de mayor talento en el teatro magrebí, demostrando durante varias décadas perseverancia e inquietud por un teatro donde converge lo físico y lo poético del cuerpo como resultado de una incesante investigación.
} 
tistas y actores entre los que se encontraba la propia autora, se movilizan y en 1975 fundan «Nouveau Théâtre de Tunis», primera compañía de carácter privado que dura una década, ya que en los 80 se ramifica en grupos de diversas tendencias y métodos que confluyen en el denominado Teatro Independiente. Baccar y Jaïbi prosiguen en solitario, y en 1993 fundan «Familia Productions».

En 1998 J.B. firma la autoría de su primer texto dramático, A la recherche de Ä̈da. La obra, que fue escrita para conmemorar el 50 aniversario de Nakba (la creación del Estado de Israel en 1948), es un monólogo, articulado a modo de fluir de conciencia de una actriz tunecina que recorre los teatros desde Túnez hasta Beirut en busca de otra actriz palestina, víctima del exilio, quien también busca sobre los escenarios su identidad y su memoria.

El paralelismo entre Palestina y Túnez se produce en la construcción de los personajes de Aïda y de la actriz tunecina, una identificación con el Otro desde el punto de vista del encierro representado en la obra, como metáfora de la soledad en la que está sumido el pueblo palestino. Aïda va al encuentro de Aïda, un recorrido por la memoria bajo la estructura de un viaje hacia el viaje recurrente, de un teatro a otro, de un país a otro. Este viaje es la imagen de un teatro que se dirige a la sociedad, hacia la posible verdad, hacia sí misma. El recorrido es un vagar errante en que dos destinos se cruzan: la una va hacia la otra, y es en este recorrido de conciencia en el que se pierde la inocencia primaria, despertándose en el personaje el compromiso político. Un destino común que une a ambos personajes hasta el punto de fusionarse.

Con la problemática palestina de trasfondo, en Araberlin (fusión de Árabe y Berlín) la autora pone de relieve el contraste identitario mediante el enfrentamiento verbal y corporal de dos grupos sociales. La obra presenta la dispersión de los puntos de vista, la ruptura, la brecha ideológica entre el Mundo Árabe y Occidente. La historia construida sobre dos ejes temáticos, la tolerancia y la emigración, narra las peripecias de un estudiante palestino residente en El Líbano. A los 25 años éste decide viajar a Alemania para acabar sus estudios de arquitectura. A su llegada a este nuevo país es interrogado por la policía y acusado de pertenecer a un grupo terrorista. El impacto que va a producir este incidente en la familia es el punto de inflexión que da pie al conflicto.

Con esta temática sensible y de actualidad, la autora hace hincapié en el debate político y plantea cuestiones acerca del individuo árabe. «Est-ce qu'on peut se faire entendre sans se faire sauter?» se pregunta la autora, al 
tiempo que expone el elemento existencial del drama: «al personaje central le es confiscado el derecho a la palabra y se le priva de libertad por tener un origen determinado» (extraído de Da Silva, 2002). La confrontación entre dos discursos ideológicos se muestra mediante la intervención de actores de ambas nacionalidades, partiendo de la idea de que el idioma, los gestos del actor y sus cualidades físicas-étnicas, son lenguajes que corroboran lo dicho y dejan evidenciar el contraste. J.B. explica que necesitaba una motivación ideológica más que artística, o sea, un discurso válido para los dos polos, algo que les una o que ideológicamente se presente como una continuidad de visiones y no de rupturas, que les permita buscar las semejanzas, profundizando en temas que afectan tanto a unos como a otros.

Para esta dramaturga, el de la generación de los 80 es un período en que todo discurso revolucionario consistía en visualizar los problemas internos a partir de la situación de Palestina como foco de injusticias; lugar donde -según palabras de esta autora (Da Silva, 2002) - confluye lo negativo de la sociedad árabe por su inmovilidad y falta de solidaridad. Al mismo tiempo, el problema de Palestina sirve como pretexto para abordar inquietudes y problemáticas que padecía la generación más joven en Túnez.

Esta problemática también es tratada en Khamssoun (Cuerpos secuestrados, 2006), como desvela el argumento de la obra. Amal, hija de padres militantes de izquierdas y educada según los preceptos laicos, se adhiere a un movimiento islamista en París, ciudad donde la joven está realizando sus estudios. De vuelta a Túnez, se ve implicada en el suicidio de su amiga, una profesora que decidió un viernes 11 de noviembre del 2005 hacerse estallar en el instituto donde trabajaba. El texto, que pone de relieve lo paradójico y las contradicciones de la sociedad tunecina contemporánea, confronta a modo de paralelismo, característica habitual en la obra de Jaïbi-Baccar, el fracaso tanto del marxismo como del extremismo religioso.

Consciente de la gravedad de la ola islamista, tal como sugiere en Khamssoun, J.B. se muestra crítica con las normas vigentes y al mismo tiempo también con los discursos radicales. Expone, sin pretender dar soluciones, la visión del ciudadano magrebí-árabe y trata la dicotomía aquí/allí desde otra perspectiva distinta a como es justificada por el logos occidental, poniendo de relieve la falta de libertad y la ausencia de comunicación de los ciudadanos árabes entre sí y en relación con Occidente. Ejemplo de esta incomunicabilidad, es el expuesto en su texto más reciente, Yahia yaïch (Amnesia , 2010). En esta obra, trata la historia de un personaje peculiar que fue víctima de un extraño incendio cuando estaba encerrado en su biblioteca. Lo 
ingresan bajo vigilancia en un hospital por confusión mental y es interrogado por los psiquiatras. Yahia debe explicar las causas del accidente, pero éste tiene dudas sobre si se trató de una tentativa de suicidio o de un robo de documentos en la biblioteca.

Entre una escritura y otra (la dramática y la escénica), la escena es la grieta entre lo frágil de una sociedad cada vez más encerrada entre sí misma y el régimen. Conocedora de la etapa de transición política y postproceso de Independencia de los años 60-80, la dramaturga se lanza con una temática que trata la ignorancia que azota a una parte de la sociedad y el silencio al que se acoge el pueblo tunecino con el fin de poder sobrevivir. La obra de esta autora, concebida para la escena conjuntamente con Jaïbi ${ }^{7}$, se inscribe dentro de lo que podemos calificar de compromiso social e ideológico. El centro en el proceso de escritura es el paradigma encuentro/desencuentro, articulado bajo la retórica de odio/amor hacia el país; también está la temática del origen, como medio para concienciar una parte de la sociedad que permanece ajena a todo compromiso. Es un teatro en el que los paralelismos y los contrastes se combinan para dar cabida a la tragedia contemporánea. Lo trágico, en este caso, para ambos dramaturgos, forma parte de la cotidianidad de unos personajes en cuya evolución se percibe la toma de conciencia de lo social.

Los personajes son un reflejo de la realidad de aquellos que viven el proceso social como una esquizofrenia entre la amenaza opresora del gobierno y la amenaza islamista. Quizás sea ésta una de las razones que lleva a esta dramaturga a adaptar Junun. Bajo este título, J.B. y Jaïbi emprenden una labor de distinta envergadura a nivel teatral (puesta en escena) y textual (los diálogos y el trabajo realizado sobre las lenguas: las dos variedades del tunecino local y el francés).

Junun es la adaptación de Chronique d'un discours schizophrène (Paris: L'Harmattan, 1999), relato autobiográfico de la psicoanalista y escritora Nejia Zemni, basado en el historial médico de Nun, joven analfabeto de 25 años de edad, enfermo de esquizofrenia y al que también se le diagnostica la sífilis. La autora recoge quince años del proceso de cura, las continuas recaí-

\footnotetext{
${ }^{7}$ Pese a que nuestro objeto de estudio son las dramaturgas, necesariamente hacemos alusión al dramaturgo Fadhel Jaïbi, porque se trata de un trabajo de colaboración conjunta. La característica fundamental que podemos resaltar en estas obras, es que se combinan ambas voces: la masculina y la femenina. Por otra parte, cuando el público acude a ver A la recherche de Ä̈da, Araberlin, Junun o Khamssoun, no lo disocia de Jaïbi, ya que, en definitiva, colabora en la escritura dramática y es responsable de la puesta en escena.
} 
das y altibajos del protagonista y la difícil relación de éste con su entorno familiar y con el cuerpo médico. «Recorrido durante el cual Nejia ha tenido que luchar contra la fatalidad del encerramiento psiquiátrico, contra la institución, la sociedad y contra sus propios demonios» (extraído de Gayot, 2002). Creada en el 2001, en coproducción con la Municipalidad de Túnez, la obra se estrena en las Jornadas Teatrales de Cartago. Se representó en diversos festivales y teatros entre los cuales destacamos los siguientes: el Berliner Festpiele (2001), el Festival Internacional de Teatro Francófono en Limousin (2001), Cloître des Célestins (2002), el Festival de Avignon (2006), el IV Festival Internacional de Buenos Aires (2003) y el Teatro Odeón en París (2006).

\subsection{Aicha Haroun Yacoubi}

Nacida en Tetuán, en 1968, esta dramaturga de origen marroquí proviene del vivero del teatro universitario. Como las otras dos autoras, también realizó estudios de Letras y una vez obtenido el diploma en la Escuela Normal Superior, se dedica a la enseñanza. En 1994 se instala en Agadir donde compagina su labor como profesora de lengua y formadora teatral de jóvenes actores hispano parlantes. En 1995 se le convoca para dirigir el primer Taller de teatro en lengua española en la Facultad de Letras de Agadir. A partir de 2003, funda la compañía «Q-Lisse Teatro», con la cual lleva a cabo el montaje de numerosos espectáculos de otros autores así como obras de su propia creación ${ }^{8}$. Para esta reciente dramaturga, la literatura dramática y la puesta en escena constituyen una misma búsqueda hacia otros territorios mediante la experimentación, dejando evidenciar, en la medida de los medios de los

\footnotetext{
${ }^{8}$ Hemos de aclarar la dificultad que conlleva esta labor tanto en el seno de una Institución como fuera de la misma, ya que supone una limitación para los autores que conciben su obra en lengua española. Si mencionamos esto, es con el fin de mostrar que la situación en la que se halla el escritor magrebí de expresión española es mucho más precaria en comparación con el escritor de expresión francófona. Es una realidad que se refleja estadísticamente si tenemos en cuenta que en Francia, cada vez hay más editoriales destinadas a los textos magrebíes. Por otra parte, también se debe al hecho de que la obra francófona en el Magreb, disfruta de salud tanto en el consumo como para su edición. No obstante, ¿qué ocurre cuando se trata de textos de expresión española? A este respecto, la universitaria Mercedes del Amo, en «El conocimiento de la literatura marroquí en España (1940-2000)», dice: «Debe prestarse mayor atención y ayuda a los escritores que escriben en lengua española, pues aunque se trate de una minoría, deben tener en nuestro país las puertas de las instituciones y de las editoriales abiertas, de acuerdo con la política española de conservación y expansión del castellano». Lo que nos llama la atención de estos propósitos, es que la estudiosa sólo menciona al género narrativo. Acerca de la obra dramática de expresión española, ésta se limita a decir: «del género teatral no existe nada traducido». Como se puede comprobar, del Amo se refiere únicamente a posibles traducciones y no a obras de creación propia.
} 
que dispone, ya que es un teatro alternativo y no subvencionado, una estética profundamente marcada por los métodos de R. Wilson, S. Sinisterra, P. Brook, etc. Directores de escena que influyeron en su manera de entender el teatro.

En su discurso, aborda temáticas que reflejan la realidad de un Marruecos anclado entre la democracia que se intenta reivindicar y los recientes recuerdos de una generación mantenida en el silencio durante los setenta y los ochenta, período que el escritor marroquí Abdelhak Serhane (1993: 10) describe con estas palabras: «Comment faire, dans un pays comme le notre? [...] Nous sommes dans une société qui impose le silence: on n'a pas le droit de parler, ni de poser des questions». Ésta, habiendo sido educada en Ceuta (España), viene a Marruecos para descubrir una sociedad oprimida por la Administración del que fuera primer ministro, Driss Basri, artífice de la ley del garrote y protagonista de los muchos atropellos y vejaciones perpetrados contra el pueblo marroquí. Este doble mundo, aquel que conoció en la infancia y ese otro que descubre una vez adulta, constituye la columna vertebral de una temática, pero también de su estética, o sea, el cómo y con qué lenguaje decir aquella herida abierta que perdura en la memoria de un colectivo.

Inicia su andadura dramática con S.O.S. Mi infancia (1997), un texto que trata sobre infancias rotas. En esta obra, la autora se inspira en la vida real de niños/as cuyo hogar es la estación de autobuses de Inezgane (una ciudad de paso para aquellos marroquíes que vienen del norte y del sur del país). Durante más de nueve meses, trabajo previo a la escritura de la obra, la autora observó el comportamiento de estos niños sin techo y las condiciones infrahumanas y violentas en que viven. Este mismo interés por el mundo infantil y juvenil, es la razón por la cual emprende la escritura de Tirra o el amuleto de Titrit $^{9}$ (2003). La obra, escrita en castellano con interferencias del beréber, trata la problemática de la explotación laboral de los niños en zonas rurales del sur de Marruecos.

En 1998, escribe Reloj de arena, un texto que relata las desventuras de cinco personajes que afrontan la dificultad de sobrevivir a los sueños, dejando atrás un viejo puerto donde las barcas son de papel. Son esas barcas que cruzan de una orilla a otra, llevándose consigo las ilusiones, pero también la vida de seres humanos. Aunque los personajes logran sobrevivir a la

\footnotetext{
${ }^{9}$ Con esta obra, traducida al gallego por el escritor y también dramaturgo, X. A. Neira Cruz, la autora participó en los Premios de teatro infantil Barriga verde, en 2004.
} 
travesía, el viaje no ha hecho más que empezar. Al otro lado del mar, comienza la búsqueda de algo que desconocen y que se traduce por el deseo de desprenderse de ese maldito reloj al que están sometidos. Un objeto que simboliza la opresión, la soledad y el miedo.

El conflicto que vehicula la obra tiene un trasfondo político que la autora presenta de manera sutil, cuidando en la medida de lo posible la presentación artística de su discurso político. Teniendo en cuenta el panorama sociopolítico en que se gestó Reloj de arena, era necesario optar por imágenes de gran elocuencia estética con el fin de no pronunciar mediante el verbo lo que no se debía decir en aquellos momentos. Nos referimos a ese Marruecos en que reinaba cierta confusión y una discreta esperanza ante la muerte inminente de una era y el comienzo de otra. Son finales de los noventa y el pueblo, que aún creía en la utopía, albergaba esperanzas en Abderrahman Yussfi, figura incontestable de aquel socialismo abatido por la dictadura de los setenta. Su vuelta del exilio y su nombramiento como primer ministro, abrió la vieja herida de los que un día creyeron en las libertades. No obstante, la Historia es pura ficción, y los poderes se suceden como modas, pero sin trascendencia ninguna. Esto explica porqué la obra empieza con esa pérdida de ideales. Los personajes saben, desde el inicio, que la espera será estéril, pero no abandonan el sueño y deciden partir desafiando el propio destino que les une a ese reloj de arena.

En los noventa y durante el gobierno de este socialista idealizado, asistimos a la degradación de la utopía socialista de antaño. A.H.Y. al igual que muchos otros artistas, también lanza un grito de ya basta, hasta cuándo, que pone, en su mayor magnitud, en boca de los personajes de otra de sus obras: Raíces del viento (2003). En el texto muestra que las sociedades son maquinarias productoras de cerebros distorsionados por una ideología u otra y el individuo se prepara para ser un producto en serie. Los personajes son seres presos del mismo encierro que ocupan aquellos que los domestican. A lo largo de la obra, éstos descubren que el mal es engendrado dentro del espacio que ocupan, por lo tanto, la salvación está en manos de Amma, personaje ambiguo que los domina sin saber que él o ella también está dominado.

En este texto, la autora se aleja de la linealidad de los acontecimientos y niega la tragedia con la caracterización de unos personajes-actores irrisorios a veces, patéticos otras. El espectáculo, que conjuga la narración épica, el juego de los actores, los espacios múltiples y el uso de varias lenguas, surgió como una reflexión acerca del control ejercido por las grandes potencias que alimentan dictaduras bajo una falsa democracia. El espacio de los personajes 
es un espejo distorsionado de la sociedad moderna de finales del siglo XX, con sus complejidades y sus inquietudes. Aspectos que también aparecen en otro de sus textos, Ghita (2004).

En Ghita, la autora relata los escollos del pasado de un personaje condenado al silencio y al encierro, en el que la espera queda en lo vano de la rutina y el abismo de la nada. La trama se concentra en el discurso atormentado de este personaje en el vacío insípido de Sidi Frej (conocido por el nombre de Mallorca): un psiquiátrico en la ciudad de Tetuán construido en la época colonial y que se conserva como huella de una represión vivida antes y después de la Independencia. Para este personaje se hace necesaria la rememoración mediante las voces ausentes de su familia en representación de un Estado, de una Patria inexistente. Los recuerdos le mantienen en vilo dentro del macabro juego entre él y la voz que surge de ninguna parte para recordarle la dosis diaria (Butterfly-personaje imaginario). El lugar que ocupa es neutro, un espacio contra el cual se subleva, evocando imágenes a las que se aferra para no perderse bajo los efectos de las drogas que le administran, la violencia a la que se ha visto sumido y el encierro al que le han llevado por engaño.

El texto, que conforma un entretejido de diversos géneros e historias, constituye una manera con que expresar la doble identidad de un pueblo con el que se identifica la propia autora, la cual trata aquella asignatura pendiente entre España y Marruecos como una brecha abierta. Con esta intención, se sumerge en la memoria de un colectivo humano que, aunque reciente en la Historia de ambos países, permanece como en el olvido. Esto nos lleva a reflexionar acerca de la obra como un ejemplo de escritura puente entre el aquí y el allí. Al decir esto, no nos referimos sólo a la geografía dramática que comporta, sino también a aquello que subyace en la escritura y que define la cosmovisión de esta autora.

\section{COSMOVISIÓN Y ESTÉTICA DRAMÁTICA DE F.G., J.B. Y}

\section{A.H.Y.}

Como toda manifestación artística, el teatro en el Magreb ha pasado por diferentes etapas: desde un teatro panfletario y de propaganda nacionalista a otras formas más vanguardistas. La corriente metodológica del teatro europeo de los 70 repercute en el trabajo de los dramaturgos y directores de escena contemporáneos que conciben la práctica teatral como ruptura con lo anterior. El resultado es una síntesis de investigaciones acerca de la mani- 
festación popular y lo adoptado del teatro occidental, un teatro sincrético ${ }^{10}$, que conjuga la tradición y la modernidad, encauzándolas desde lo multicultural como verdadera identidad del magrebí.

El entrecruce de culturas se produce una vez que la línea fronteriza entre el yo y el Otro se permeabiliza: hombre-mujer, Oriente-Occidente, tradiciónmodernidad, o mi lengua y la lengua del Otro, etc. Teniendo en cuenta que según de Toro (2001: 17), la colonización es una expansión globalizante que transformó los lenguajes y culturas de las periferias y del centro y que afectó todas las estructuras sociales así como las del arte en general, este fenómeno social y político de la colonización influyó directa e indirectamente en la creación magrebí de la segunda mitad del siglo XX, fecha a partir de la cual surge una corriente literaria y teatral importante que pone de relieve la pluralidad lingüística y cultural propia de la identidad mestiza del Magreb. El fenómeno repercute en la obra del artista y del escritor que adopta el lenguaje colonizador impuesto durante décadas, como manifestación del ego frente a dicha imposición. Es un período de posesión y desposesión cultural e identitaria como diría Raja Alloula (1996: 32): «la administración colonial -explica esta pensadora- emprendía toda clase de acciones con el fin de desposeer a los argelinos de sus bienes, de explotarlos, de marginarlos, de ignorar todos los valores culturales ancestrales a los que estaban vinculados». El colonialismo como elemento histórico-político ha afectado toda la cobertura social y tradicional también en países como Túnez, Argelia y Marruecos, influyendo considerablemente en las estructuras sociales y en la literatura como manifestación del pensamiento magrebí.

En los textos de estas autoras se escenifica la contestación femenina contra las normas de la tradición y del sistema político e ideológico implantado. Teniendo en cuenta los postulados que la crítica postcolonial ofrece, su

${ }^{10} \mathrm{Al}$ emplear el término sincrético, lo hacemos partiendo de la definición de Alfonso de Toro, un «teatro y estrategia de mezclas postcoloniales, como recodificaciones (y equivale a nuestra definición de hibridez) [...] es más bien una experiencia social, histórica y antropológica entendida como resultado de un hecho colonizador sui generis y por esto no una operación cultural intencionada. El sincretismo es una superposición voluntaria o involuntaria de diferentes culturas» (2001: 20). Éste es un teatro marcado por lo propio del magrebí que es una amalgama de culturas y lenguas como procesos que se fusionan y que configuran una identidad. Se trata de un proceso común a todos aquellos países en que las culturas autóctonas constituyen la base de un logos distinto al occidental que se mezcla con otras culturas impuestas durante el fenómeno colonial, como puede ser el teatro latinoamericano que García Canclini define en cuanto «una articulación más compleja de tradiciones y modernidades (diversas, desiguales), un continente heterogéneo formado por países donde, en cada uno, coexisten múltiples lógicas de desarrollo. Para repensar esta heterogeneidad es útil la reflexión [...] del postmodernismo, más radical que cualquier otra anterior» (extraído de Toro, 2001: 20-22). 
discurso «lleva un profundo cuestionamiento de los metadiscursos autoritarios y legitimistas» que, según de Toro (2001: 13), conforma «el pensamiento post-moderno que a su vez deriva de la disolución del Logos expuesta en las obras de Lacan, Derrida y Foucault». Encontramos la verdadera esencia de un teatro de la diferencia y alteridad en estas autoras, las cuales, conscientes o no de las características propias de este teatro, se incluyen ellas mismas en una estética postmoderna. Continuando esta línea de reflexión, mostraremos en los apartados que siguen cuáles son las marcas identitarias y cómo éstas se hallan inscritas en el discurso de las mismas a través de la temática, los personajes y el lenguaje.

\subsection{Temática}

Como hemos podido observar en el epígrafe anterior, las obras de estas autoras dan testimonio de la época que vive la sociedad actual en el Magreb. En los textos se pone de relieve una temática que muestra los distintos procesos sociales, ideológicos y económicos por los que está atravesando el magrebí, el cual se halla atrapado entre lo heredado como tradición y la modernidad a la que aspira. Este contexto problemático se presenta en el interior del texto, a través de personajes en situación de conflicto ya sea con el sistema, con la institución y aquellos valores tradicionales que ya no son válidos en la actualidad o aquellos otros que son impostados y que constituyen una modernidad opresiva.

El conflicto viene producido por causas internas a la propia sociedad de la que habla el texto, que no es necesariamente en su relación con Occidente, tal como podemos comprobar en la ruptura expresada con la disyuntiva aquí/allí que algunos tradicionalistas achacan a una lógica importada de Occidente, pero que, sin embargo, es válida para el contexto en que se desenvuelve el individuo magrebí, el cual aún se debate por el derecho a la palabra. Hay una necesidad de proclamar la libertad frente al sujeto dominante que en los textos viene representado simbólicamente en la figura del padre y en la interacción con la madre; ambas metáforas de ley y nación respectivamente. De manera que ya no se mide el paradigma poder en relación a Occidente, sino en relación con la fuerza de sumisión y subyugación del cuerpo relegado ${ }^{11}$, reducido a la invisibilidad.

${ }^{11}$ Este cuerpo relegado es el mismo que G. Spivak define como lo subalterno (véase «Can the subaltern Speak?», 1988: 271-313). 
El paradigma masculino/femenino no se establece a partir del rasgo de sexualidad que diferencia macho/hembra; y, a su vez, el paradigma poder/sometimiento no se corresponde necesariamente con la alternativa entre masculino y femenino. Esta revisión es una de las características de esta nueva dramaturgia, que replantea las categorías establecidas bajo una óptica político-social. De modo que las dramaturgas conciben la escritura como un campo de investigación sobre la relación con la Otredad. Las alternativas occidente/oriente, blanco/negro, mujer/hombre, constituyen paradigmas de los que se hacen valer estas autoras que vienen a coincidir en que nuestros comportamientos guardan relación con el bien y el mal.

\subsection{Personajes}

Dentro de la corriente de realismo crítico, nuestras autoras optan por personajes marginales condenados al encierro, a la soledad, seres desvalidos que buscan llenar vacíos internos o despojarse de fantasmas del pasado, encontrarse a sí mismos con la ayuda de los otros que están más desamparados o perdidos.

En los textos de F.G., el personaje femenino actúa como centro de la escritura. El elemento mujer es desencadenante del conflicto y eje de la acción. No obstante, lo femenino puede ser entendido en su aspecto simbólico, como metáfora de lo marginal, de modo que en este paradigma entrarían todos aquellos personajes, masculinos y femeninos, cuyo rasgo común revela que son seres negados mediante la acción o la palabra. Es decir, los personajes son seres a quienes se les confisca la palabra y la voluntad de hacer por medio del encierro o la discapacidad física, moral o mental.

En los textos de J.B. y A.H.Y. lo femenino también se considera en su aspecto simbólico que trasciende a una realidad. Para estas autoras, la mujer es un tema implícito por cuanto forma parte de una concepción del ser humano que se debate por la existencia, de ahí que podemos decir que las oposiciones de identidad no ocupan el centro de atención y las entidades mujer/hombre se permeabilizan. Dicha permeabilización la consideramos como un acto de posesión cultural e identitaria, que las autoras llevan a cabo a través de personajes que se sustraen al poder neocolonial ${ }^{12}$. Es la válvula de escape de las

${ }^{12}$ Partiendo de las ideas de Spivak sobre lo subalterno, el cambio que se produce es del sujeto colonial a otro postcolonial, los discursos son los mismos y la jerarquización perenniza los valores ya establecidos en la etapa colonial. Es decir, la distribución de los roles sociales permanece fuertemente vinculada al poder del sujeto dominante: el que representa el Padre. 
autoras que fortalecen el mecanismo de ruptura con lo ya existente independientemente del sexo de los personajes.

Entendemos que este uso que se hace del personaje y los otros elementos de composición del texto ${ }^{13}$, también conlleva implícito un cuestionamiento del teatro y la escritura dramática actual. Los personajes son de índole diversa, híbrida y polifónica, y se van construyendo, a lo largo de la obra, a través del conflicto que genera el choque de culturas, de creencias, de supersticiones, así como el enfrentamiento generacional, etc. Se evita el estereotipo y se emprende un viaje en busca de la interioridad, al tiempo que se retrata una sociedad cuya modernidad es contradictoria. Los elementos, tanto de la interioridad como de la contradicción, son las piezas del puzle del logos magrebí, femenino y masculino, que cuando se logren ensamblar harán emerger una verdad otra.

F.G., manifiesta la necesidad de abrirse al Otro recurriendo a personajes de distintas procedencias -como por ejemplo la protagonista de Molly des sables o las protagonistas de Richesses de l'hiver- y diversas creencias religiosas, mediante los cuales plantea la confrontación entre las visiones tradicionalista y modernista. También se observa la problemática surgida de la relación entre la creencia cristiana e islámica, tal como puede verse en Princesses, obra que trata sobre un debate entre una mentalidad abierta y occidentalizada de la protagonista y otra más conservadora de las Ancianas. Pero, también, esto enriquece la visión de la problemática y es que dentro de las relaciones hay conflictos del tipo que se da entre musulmanes que se alejan de la religión por mantener creencias extremas o supersticiones tal como sucede en Les coépouses, Amour et Talisman, Fête virile, etc.

En J.B., la opción por una cultura u otra, también se ve apoyada por la atribución de orígenes y procedencias diversas al personaje. La autora relaciona personajes de distintos pueblos árabes e intenta que éstos adquieran ese aire de no pertenecer a ningún límite fronterizo, lo que ella denomina nolands, aunque, si profundizamos en su obra, hallamos un fuerte arraigo con

${ }^{13}$ Tanto en el personaje como en los otros elementos de la composición del texto se observa un deslizamiento de fronteras. Al respecto, de Toro señala: «la huella de la diferencia describe la claudicación del logos metafísico occidental, y con esto el dualismo, favoreciendo tanto la diferancia (Derrida), la alteridad (Taylor) como también un pensamiento nómada y transversal por lo que categorías binarias excluyentes tales como periferia vs centro o masculino vs femenino ya no tienen legitimización o son fuertemente cuestionadas. Las fronteras se permeabilizan para el Marginado, para las Orillas y para la Otredad en general» (2001: 13-14). Mediante sus personajes, además de otros elementos de composición, las autoras rompen el cordón umbilical con la cultura del padre -o de la madre, puesto que ésta funciona como sujeto que actúa por delegación de la ley masculina-. 
Túnez en primer lugar y el Mundo Árabe en general. Es en A la recherche de Aïda, donde se produce esta identificación con mayor fuerza: la del personaje real con la del personaje evocado. La comunión entre ambos personajes establece un paralelismo entre Túnez y Palestina. Ambas mujeres conforman un único cuerpo donde se escribe la historia de dos países con lazos complejos que nos revelan la identidad del Mundo Árabe. En cambio, en otras creaciones como Junun, Khamssoun y Yahia yaïch, se pone más énfasis en el individuo tunecino en concreto. El conflicto es expresado a través del enfrentamiento entre personajes, retrato de la sociedad tunecina que se debate contra sí misma y contra el sistema.

En cuanto a A.H.Y, concibe a sus personajes como seres desarraigados y esto se transmite precisamente en la ambigüedad que muestran los mismos. En un nivel más profundo del texto, no ya de los personajes o de los actantes, sino en el de la lógica elemental, se establecen y se neutralizan oposiciones del tipo blanco/negro, norte/sur, mujer/hombre, poderoso/sometido, etc., creando así oposiciones y alternativas allí donde la ideología nos la oculta.

La geografía dramática, donde sucede la acción y se desenvuelven los personajes, no siempre es explicitada en su obra, esto responde quizás a un intento de no ubicarlos en ninguna parte o visto de otro modo, a una búsqueda de identidad plural que a veces se pierde entre las exigencias de la universalidad, la globalización y otros inventos actuales. En Ghita, por ejemplo, pese a que la acción se sitúa en alguna parte de Marruecos, el único personaje presente en escena está preso en un laberíntico pasaje por las diversas personalidades en las que se transforma, volviendo al lugar de la nada, aquel punto donde no puede encontrar a su hermana en las turbulentas aguas del pasado. Su travestismo no es sólo físico, sino también moral y psicológico. Errando por aquellas sensaciones que pudo vivir la hermana, se integra en un espacio de la psique femenina hasta el punto de sentir lo que únicamente una mujer puede sentir: el parto de su otro yo o las primeras sangres.

\subsection{La lengua como marca identitaria}

Al igual que las temáticas y las estructuras del personaje, la lengua es también una marca que caracteriza a estas obras como partícipes de las poéticas postcoloniales.

La literatura contemporánea en el Magreb conoce su auge a partir del fenómeno colonial, siendo la lengua extranjera un medio de expresión por el que optan muchos autores, especialmente los que han adquirido la doble cul- 
tura. Ésta es una de las motivaciones por las que, en vísperas de la Independencia, los gobiernos se movilizan en pro de la arabización como la vuelta a la legitimidad de una cultura y un pueblo. Al ser éste un proceso unificador que margina las herencias y las lenguas maternas (nos referimos a las lenguas locales), genera inconformismo por parte de unos y sentimiento de culpabilidad por otros que manifiestan abiertamente, como es el caso del humorista Mohamed Fellag en «Entretien avec Mohamed Fellag -Créer dans l'urgence pour devancer la morale»:

C'est ma vraie langue le mélange des trois langues, c'est ma langue; c'est ça que je parle naturellement, et elle est comprise naturellement, parce que le public est comme moi... Je suis contre tous les purismes, je suis pour le mélange, je suis pour l'utilisation libre de toute contrainte. Je ne suis pas linguiste, mais je pense que c'est comme ça que les langues se sont faites, en se mélangeant à d'autres langues (Caubet, 2004: 39).

Los artistas hacen que su expresión sea un medio de revelar una identidad que conlleva un proceso que A. de Toro (2001:19) define como «el rodar de unidades culturales que no se dejan reducir a un origen cultural o étnico único [...] La diferencia ya no es un proceso que implica exclusión, sino todo lo contrario, repliega el material canónico, injerta y no elimina». De modo que, y teniendo en cuenta los fundamentos de este estudioso, no ha de extrañarnos el surgimiento cada vez más importante de una producción artística (teatro, música y cine) en las lenguas de uso coloquial tan plagadas de elementos culturales y lingüísticos de otras variedades lingüísticas. ¿Pero qué sucede cuando se trata de literatura?

En literatura, el problema identitario se halla como centro en el proceso de escritura, característica común en autores como Assía Djebar, Mohamed Dib, Kateb Yacine, Taher Ben Jelloun, Mohamed Kheir-dinne, entre otros muchos, los cuales representan una escritura de estética postcolonial caracterizada por el uso de la lengua del Otro. La lengua francesa, según Lamia Azzouz (1998), forma parte de la personalidad del que escribe porque no elimina todo aquello que fue adquiriendo desde su infancia sólo para adecuarse a lo hegemónico. La lengua, como factor de identidad que une el autor/a a una doble y hasta triple cultura, produce una esquizofrenia vivida internamente por el/la magrebí como diría el dramaturgo argelino Aziz Chouaki en «À propos d'Une Virée» (2006):

Contre la purification ethnique, je revendique une langue impure, sexuée, bâtarde, mêlée comme le créole [...] quand je suis en période d'écriture, les 
quatre langues de mon pays crient 'Présent!' dans ma tête [...] Me bricoler une écriture qui serait une espèce de zone franche des langues, tel est mon idéal.

La dialéctica es el rasgo común entre escritores, dramaturgos y artistas, en general, que persiguen fines diversos, tales como hacer llegar su creación a un público más amplio, pero también otros fines más personales como en la escritura que surge del inconsciente, en la que influye la coyuntura sociocultural a la que pertenecen, como se puede comprobar en los textos de estas tres autoras.

F.G. escribe exclusivamente en francés con un dominio del habla francoargelino tal cual se heredó del período colonial y el que siguen usando en las kábilas como se puede apreciar en Princesses. Temáticamente presenta elementos que hablan de un proceso, aquél con el que se ha germinado toda una generación de argelinos de doble y hasta triple identidad. Gallaire, al igual que muchos de sus coetáneos, da muestras de un sentimiento de culpabilidad provocado por la fisura de su identidad franco-argelina como explica Anne Schmidt en la cita siguiente:

Certes, cette critique ne concerne pas seulement Fatima Gallaire, d'autres auteur(e) s du Maghreb font la même expérience. Pourtant cela n'empêche pas un sentiment de culpabilité et de manque. Ces effets pervers d'une double identité sur le plan linguistique s'aggravent par la décision du gouvernement algérien d'imposer l'arabisation du pays, à partir de l'été 1998 (Schmidt, 1998b).

Comparte este rasgo la hispanófona A.H.Y. Las huellas de la lengua materna también aparecen en los textos hispanófonos ${ }^{14}$ como es el caso de los de esta autora. Y esto es lo que, en definitiva, da un carácter particular a una escritura que ella califica de huérfana por sentirse abandonada por el Pa-

${ }^{14}$ Acerca de esta literatura sostenemos que la cuestión del lenguaje y de la identidad es también objeto de reflexión del proyecto literario para los escritores hispanófonos bilingües: una escisión o ruptura como consecuencia de una relación compleja que el escritor mantiene con la lengua española y la lengua materna. Por motivos que aún no han sido definidos, los estudios, en su mayoría, se refieren a los escritores francófonos y atienden a la compleja relación mantenida con la lengua francesa que parece relevante en todos los ámbitos y sectores de la sociedad magrebí. Sin embargo ¿qué ocurre con los que también mantienen lazos con la lengua española? En los estudios de lingüística aplicada se ha demostrado que la lengua española está presente especialmente en el discurso del marroquí: léxico de pesca, tecnicismos en el ámbito industrial, así como en el habla cotidiana tanto en el norte del país como en la zona sur próxima al Sáhara. 
dre biológico y por el Padre adoptivo. A la pérdida del padre real se suma otra simbólica de orden lingüístico que la autora refleja mediante el uso de una tercera lengua, poniendo de relieve el yo que se halla situado entre el aquí y el allí y que no alcanza a pertenecer a ningún lado. De hecho así lo corrobora esta última en la cita siguiente:

Crecí y me eduqué en el seno de una familia que siempre ha empleado el switching para expresarse, algo que surge del inconsciente y supone una mezcla de ambas identidades [...] Esto es lo que concibo como doble identidad, lejos de ser una esquizofrenia, para mí es un territorio distinto del marcado por la geografía y las políticas, por las estúpidas y convencionales fronteras (extraído de Nachawati, 2010).

En cuanto a J.B., escribe en árabe y es traducida al francés por Fadhel Jaïbi. Aunque el uso que ambas dramaturgas hacen de la lengua, empleando el dialecto tunecino, el francés y la lengua árabe, ya no responde al mismo proceso que el de las dos autoras anteriores, sino que más bien responde a la necesidad de hacer circular un espectáculo, como explica el mencionado director de escena y en este efecto también traductor: «Nous jouons en arabe sur titré, avec trois niveaux de langage, le tunisien citadin, le tunisien bédouin [...] et l'arabe littéraire» (extraído de Gayot: 2002). No obstante, en dicho proceso de trascripción y traducción de un idioma a otro, de un registro lingüístico a otro, siempre actúa como centro el carácter y personalidad de lo magrebí.

\section{CONCLUSIONES}

En el Magreb existe una voz femenina que tiene su eco progresivamente en el sistema teatral y literario. Se trata de autoras que implícita y explícitamente reivindican un teatro, un discurso y una visión del mundo. Esto no quiere decir que a los textos de las dramaturgas se les otorgue el reconocimiento conveniente. Para que esto ocurra, se necesita una evolución más profunda de la mentalidad del lector magrebí, pero sobre todo del crítico, el cual se mantiene reacio a reconocer la obra escrita por mujeres. Escépticos en cuanto a las valoraciones y juicios existentes hasta el momento acerca de esta escritura, intentamos que de un modo indirecto quede mostrada la arbitrariedad a la que están sujetos estos juicios. Para ello, y puesto que en el Magreb aún no se ha llevado a cabo el estudio de esta escritura, en el presente artículo hemos intentado contribuir a una aproximación crítica a la obra de 
tres dramaturgas de origen magrebí, poniendo de relieve los rasgos culturales, ideológicos e identirarios que le son propios.

Pues bien, a partir del postcolonialismo como criterio definitorio, las dramaturgas magrebíes, aunque en un período posterior al fenómeno colonial, heredan una serie de influencias propias de las tendencias literaria y teatrales que fueron surgiendo en sus respectivos países. Reinventando una realidad que también les ha tocado vivir y que se traduce en otro proceso del discurso postcolonial como es el de los cambios drásticos en la mentalidad y costumbres de la sociedad y la reimplantación de la tradición y la lengua como espacio legítimo. En las obras de estas autoras aparecen ciertos elementos de heterogeneidad, que manifiestan que se trata de tres estéticas de escritura distintas, relacionadas con la cosmovisión de las mismas, en cuyos discursos se hallan inscritas marcas identitarias puestas de relieve en la temática, los personajes y el lenguaje.

En suma, estamos ante el teatro de una cultura compleja que articula tradición y modernidad, dentro de la cual intervienen las voces de mujeres que pretenden alejarse de algún modo de la visión estereotipada del lugar de la mujer en la cultura. Es un teatro que se corresponde con una escritura contemporánea femenina, de la cual seleccionamos las mencionadas autoras y a sus obras. A través de ellas, actualizamos el debate sobre la dualidad masculino-femenino. Pues mediante personajes, que no son necesariamente mujeres y sus conflictos, intentan permeabilizar las fronteras entre un lado y otro del paradigma, tendiendo a la disolubilidad de ambos discursos. De este modo, lo femenino, en la obra de las citadas dramaturgas, ya no sólo responde a la categoría de código, sino que actúa como eje en el mismo proceso de creación; y esto es así, independientemente del sexo de los personajes, de la situación dramática y de la motivación que les lleva a romper con la tradición, a veces no violando las normas, sino transformándolas.

\section{REFERENCIAS BIBLIOGRÁFICAS}

ABI SAHB, B. (1996). «Cuatro experiencias del teatro tunecino de vanguardia». Primer Acto 266, noviembre-diciembre, 24-31.

ALLOULA, R. (1996). «Una aproximación histórica», Rocío Utray (trad.). Primer Acto 266, noviembre-diciembre, 32-36.

AZZOUZ, E. L. (1998). Écritures féminines algeriennes de langue françaises (1980-1997): mémoires voix resurgies, narrations specifiques, Thèse 
de Doctorat, Arlette Cheman (dir.). Oslo: Université Nice-Sophia Antipolis (tambien en http://www.limag. refer.org/Theses/Azzouz.PDF).

BACCAR, J. (1998). A la recherche de Ä̈da. Paris: Les Solitaires Intempestifs.

(2003). Araberlin. Paris: Éditions Théâtrales, Passages Francophones.

__ (2004). Junun (Démences). Paris: Éditions Théâtrales, Passages Francophones.

_- (2007). Khamsoun. Tunis: Sud Éditions Tunis (en árabe).

BERENGUER, Á. (1999). «El teatro y su historia: reflexiones metodológicas para el estudio de la creación teatral española durante el siglo XX». Las Puertas del Drama 0, otoño, 4-17.

CAUBET, D. (2004). «Entretiens avec Mohamed Fellag». En Les mots du Bled, 27-59. Paris: L'Harmattan.

DA SILVA, M. (2002). «Libres propos de Jalila Baccar». L'Humanité, 16 septembre (también en http://www.humanite.presse.fr/popupprint.php3?idarticle=448334).

ESCUDOS, J. (2003). «¿Subversión, moda o discriminación?: sobre el concepto Literatura de género». ISTMO. Revista virtual de estudios literarios y culturales centroamericanos (http://www.wooster.edu/istmo/foro/subversión.htm).

GALLAIRE, F. (1987). Témoignage contre un homme stérile. L'Avant-scène Théâtre 815, octobre.

- (1988). Princesses. Paris: Éditions des Quatre-Vents.

- (1990). Les Coépouses. Paris: Éditions des Quatre-Vents.

- (1993). Amour et Talisman. Théâtre et Nouvelles. Mohammedia: Ateliers Revue des Facultés.

- (1994). Molly des Sables. L'Avant-scène Théâtre 954, juillet.

- (2003). La beauté de l'icône. Paris: Éditions Art et Comédie.

GAYOT, J. (2002). «Entretient avec Fadhel Jaïbi: Junun (Démences)». Passion Théâtre (http://www.passion-theatre.org/cgi-bin/pti_lol/spectaclelaffichelfiche.pl?id_planning=6371).

HAROUN YACOUBI, A. (2010). Ghita. Alhucema (Granada: Dauro) 23, enero-junio, 247-279. 
LO PORTO, V. M. (2012). «Puesta en escena de obras de dramaturgas en la cartelera de ABC de Madrid (1990)». Signa. Revista de la Asociación Española de Semiótica 21, 369-393 (también en http://descargas.cervante s virtual.com/servlet/Sirve Obras /12715737554944883087402/047379.pdf?incr=1).

MDARHI, A. (2001). «Approche du roman féminin au Maroc: historique, dénomination et réception de la littérature féminine». Actes du Colloque Ecritures Féminines au Maroc. Études et Bibliographie (CCLMC), Bulletin de liaison (Rabat) 4-5 (también en http://www.limag.refer/org/texte/htm).

NACHAWATI, L. (2010). «Aicha Yacobi: cuestionando fronteras a través del teatro». Alianzas. Periodismo Humano (en http://alianzas.periodismohumano.com/2010/12/13/aicha-el-yacoubi-cuestionando-fronterasa-traves-del-teatro/).

ROMERA CASTILLO, J. ed. (2012). «Estado de la cuestión 2. Sobre teatro breve de hoy y obras de dramaturgas en la cartelera madrileña (1990 y 2000)». Signa. Revista de la Asociación Española de Semiótica 21, 199204 (también en http://descargas. cervantesvirtual.com/servlet/SirveObras/010486305412542030 38813/047376.pdf?incr=1).

SERHANE, A. y GALLAIRE, F. (1993). Théâtre et Nouvelles. Mohammedia: Ateliers Revue des Facultés.

TORO, A. de (2001). «Reflexiones sobre fundamentos de investigación transdisciplinaria, transcultural y transtextual en las ciencias del teatro». Gestos 32, noviembre, 11-46.

SCHMIDT, A. (1998a). Le miroir de l'autre: une nouvelle génération de femmes dramaturges issue de la migration à Paris au XXème siècle, Thèse du Doctorat, Martin Rougemont (dir.). Paris III (también en http://www.limag. refer.org/Theses/Schmidt.htm).

- (1998b). «Fatima Gallaire: A la recherche de la langue perdue». Études Littéraires, Bulletin de Liaison, 16-17 (también en http://www.limag.refer.org/Bulletin/Bulletin1617DocTravail.htm).

SPIVAK, Ch. G. (1988). «Can the subaltern Speak?». En Marxism and the interpretation of culture, Cary Nelson; Lawrence Grossberg (eds.), 271313. Urbana: University of Illinois Press. 


\section{REFERENCIAS EN INTERNET}

http://www.cervantesvirtual.com/hemeroteca/signa.

http://www.uned.es/centro-investigacion-SELITEN@T/estudios _sobre_teatro.html.

http://www.limag.refer/org/.

http://www.startheatre.fr/public/Molly_des_Sables/Molly_des_Sables_Cie_I.

_Starkier.pdf.

http://www.theatre-contemporaine.net/spectacles/viree/presentation.htm.

Recibido el 23 de mayo de 2012

Aceptado el 30 de septiembre de 2012 
